\title{
Industrial Feasiblity of Direct Methane Conversion to Hydrocarbons over Fe-Based Fischer Tropsch Catalyst
}

\author{
Ademola M. Rabiu, Isa M. Yusuf \\ Department of Chemical Engineering, Cape Peninsula University of Technology, Cape Town 8001, South Africa. \\ Email:RabiuA@cput.ac.za
}

Received September 2013

\begin{abstract}
Recently, as a direct consequence of the dwindling world oil reserves and the growing awareness of the environmental problems associated with the use of coal as energy source, there is growing interest in cheaper, abundant and cleaner burning methane. The Gas-to-Liquid technology offers perhaps the most attractive routes for the exploitation of the world huge and growing natural gas resources. Using this process the erstwhile stranded gas is converted to premium grade liquid fuels and chemicals that are easily transported. However, a widespread application of the GTL process is being hampered by economical and technical challenges. The high cost of synthesis gas, for instance, weighs heavily on the economics and competitiveness of the process limiting its wider application. This work presented a modified Gas-to-Liquid process that eliminates the costly synthesis gas production step. The proposed process utilized an alternative pathway for methane activation via the production of chloromethane derivatives which are then converted to hydrocarbons. It established that hydrocarbons mainly olefins can be economically produced from di- and tri-chloromethanes over a typical iron-based Fischer Tropsch catalysts in a moving bed reactor at industrially relevant conditions. Some of the attractions of the proposed process include a) the elimination of the costly air separation plant requirement b) high process selectivity and c) significant reduction of carbon dioxide emissions thereby saving on feedstock loss and the costly $\mathrm{CO}_{2}$ removal and isolation processes.
\end{abstract}

Keywords: Gas-to-Liquid; Methane Chlorination; Synthesis Gas; Olefinic Hydrocarbons; Iron-Based Catalyst; Moving-Bed Reactor; Deacon Process; Carbon-Dioxide Emission

\section{Introduction}

The discovery of more stranded gas resources and dwindling oil reserves, have spurred the growing interest in the Gas-to-Liquid (GTL) technology [1,2]. The world proven reserve of natural gas at the end of 2012 stands at 6800 trillion cubic foot (tcf) [3,4] that is, about 3196 billion barrels of oil equivalent. This estimates more than double the crude oil reserves of around 1669 billion barrels [3]. However, a total of 2612 tcf of this reserve [5], more than 38 per cent are stranded [6], that is, in remote locations far from existing markets, transportation and processing infrastructures. In addition, a large amount of gas is typically co-produced with crude oil as associated gas. In many cases, the gas is routinely flared resulting in a huge loss of revenue and serious environmental consequences due to the greenhouse gases produced. It has been estimated that the amount of gas being flared in Africa could produce 200 Terawatt hours (TWh) of power, about 50 per cent of the whole continent's power consumption $[9,10]$. Natural gas flaring worsens the global warming problem by significantly increasing the emis- sion of greenhouse gases and volatile organic compounds. A World Bank report estimated that natural gas flaring is responsible for about 10 per cent of the global $\mathrm{CO}_{2}$ emission [9]. Converting the natural gas resources on-site into liquid products becomes attractive. Compare to natural gas, the liquid products are relatively easier to handle, they can be transported using existing infrastructures [7, 8,11 ] and have a higher energy density. One of the most attractive routes for conversion of natural gas is the Gasto-Liquids technology $[12,13]$. The growing world gas resource has resulted in construction of more GTL plants $[11,14]$.

The GTL technology includes a group of processes that convert natural gas into liquid products [15]. Most of these processes are scalable and hence offers an attractive route to monetize even a relatively small deposit of natural gas. The technology involves direct $[16,17]$ and indirect $[7,18,19]$ conversion of methane to synthetic liquid products. The direct route involves methane direct conversion into valuable chemicals and chemical intermediates, for instance catalytic oxidation of methane to 
produce methanol. The indirect conversion via synthesis gas has gained more attention for the production of high premium transportation fuels. Rapid technology development has led to significant technological advances in the GTL technology. While these advancements have added new insights resulting in overall process improvement [20], the heavy dependency on the cost of raw materials still remains an economic challenge [21,22]. The production of syngas together with the required air separation unit and the eventual $\mathrm{CO}_{2}$ removal, is the most capital and energy intensive of the overall GTL process [22-24], accounting for between $55 \%$ - 70\% of the total capital investment and running costs of the plant $[24,25]$. Another drawback of the syngas conversion route is the production and emission of relatively large amounts of $\mathrm{CO}_{2}$. In the reforming plant, about $20 \%$ of the carbon is converted to $\mathrm{CO}_{2}$ [26].

This study is motivated by the economic challenges posed by the costly synthesis gas production step, the loss of feedstock as carbon dioxide, and the environmental challenges of the $\mathrm{CO}_{2}$ emission, associated with typical FT plants. A modified Gas-to-Liquid technology that eliminates the use of synthesis gas is proposed. This process provides insight into a potential route for commercial application of a modified GTL process where the costly synthesis gas is replaced by chloromethanes and directly converted to hydrocarbons, either in the presence or absence of hydrogen. The proposed process exhibits important advantages over the typical process. It eliminates the air separation unit which in a GTL plant is the unit with the highest capital investment. Apart from the significant environmental benefit due to zero $\mathrm{CO}_{2}$ emissions, the process obviates the need for the costly $\mathrm{CO}_{2}$ removal and isolation plants. The result is a process that is greener, more energy efficient and economical for natural gas conversion to liquid fuels and chemicals.

\section{The Modified Gas-to-Liquid Process}

The modified process for the conversion of natural gas to transportation fuels and chemicals consists of three principal steps-production of chloromethane compounds; conversion of the chloromethanes to hydrocarbons, and lastly, chlorine recovery. The first step involves gas phase thermal or catalytic selective chlorination of methane to predominantly di-chloromethane and tri-chloromethane. The monochloromethane is separated and recycled. Secondly, the chloromethane is fed into a moving-bed reactor packed with iron-based FT catalyst and wherein it is converted to predominantly olefinic hydrocarbons FT products and $\mathrm{HCl}$ gas, at industrial relevant conditions. The $\mathrm{HCl}$ by-product is separated from the FT products to obtain premium fuels with permissichlorine content. The process features a close chlorine loop. The Deacon reac- tion is used to recover chlorine from the hydrogen chloride byproduct, so that effectively there is no net consumption of chlorine in the overall process. Finally, the plant employs a hydrolyser to regenerate the chloride catalyst. The process flow diagram is presented in Figure 1. The overall reaction can be represented as:

$$
\mathrm{CH}_{4}+\mathrm{O}_{2}(\text { air }) \rightarrow \mathrm{C}_{\mathrm{n}} \mathrm{H}_{2 \mathrm{n}}+\mathrm{H}_{2} \mathrm{O}
$$

Consisting of the following independent steps:

$$
\begin{gathered}
\mathrm{CH}_{4}+\mathrm{Cl}_{2} \rightarrow \mathrm{CH}_{2} \mathrm{Cl}_{2}+\mathrm{CHCl}_{3}+\mathrm{HCl} \\
\mathrm{CH}_{2} \mathrm{Cl}_{2}+\mathrm{CHCl}_{3} \rightarrow \mathrm{C}_{\mathrm{n}} \mathrm{H}_{2 \mathrm{n}}+\mathrm{HCl} \\
\mathrm{HCl}+\mathrm{O}_{2} \rightarrow \mathrm{Cl}_{2}+\mathrm{H}_{2} \mathrm{O}
\end{gathered}
$$

The process features an excellent process integration to minimize utilities requirement. The process consists of established technologies hence only salient points as relate to choice of reacting system and operating conditions will be mentioned as appropriate. The production of hydrocarbon over the iron catalyst will be mentioned in details however.

\subsection{Production of Chloromethanes}

Methane (typical of alkanes) undergoes very few reactions. One of these reactions is halogenation, or the substitution of hydrogen with halogen to form a halomethane. This is a very important reaction providing alternative pathway for methane activation for the production of synthetic crude, fuels and chemicals. Industrial use of this process will not only eliminate the expensive air separation plants, but as well produce far less greenhouse gases. Gas phase thermal oxidation $[27,28]$ and catalytic oxidative methanation [29] process are suitable for industrial application. The proposed process is based on elimination of need for air separation for oxygen production, hence the gas phase thermal chlorination is selected.

Methane chlorination is a radical reaction characterised by poor selectivity [27], forming a products stream consisting of equilibrium concentration of all the chloromethanes as shown in Equations 2:

$$
\begin{array}{r}
\mathrm{CH}_{4}+\mathrm{Cl}_{2} \rightarrow \mathrm{CH}_{3} \mathrm{Cl}+\mathrm{HCl} \\
\mathrm{CH}_{3} \mathrm{Cl}+\mathrm{Cl}_{2} \rightarrow \mathrm{CH}_{2} \mathrm{Cl}_{2}+\mathrm{HCl} \\
\mathrm{CH}_{2} \mathrm{Cl}_{2}+\mathrm{Cl}_{2} \rightarrow \mathrm{CHCl}_{3}+\mathrm{HCl} \\
\mathrm{CHCl}_{3}+\mathrm{Cl}_{2} \rightarrow \mathrm{CCl}_{4}+\mathrm{HCl}
\end{array}
$$

One way to influence the product ratios is to control the moles of chlorine used and the process conditions. It has been reported that, except for reaction 2.4 , the products will contain all the chloromethanes $[6,27,30,31]$. The process conditions chosen to maximize the proportions of di- and tri-chloromethanes were as reported by Rozanov and Treger [27]. Methyl chloride was separated from the products and recycled with unreacted methane. Over Fe- 


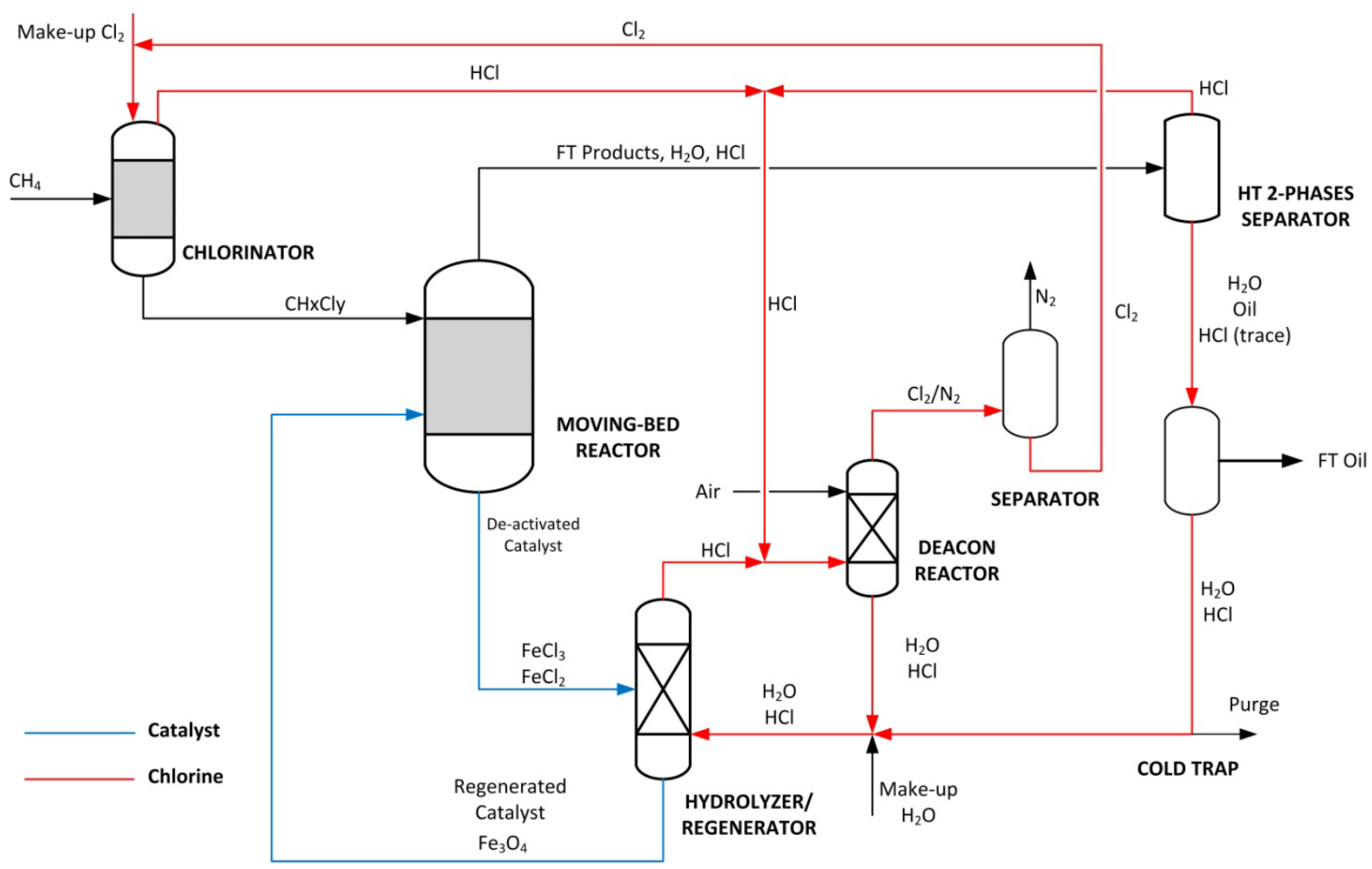

Figure 1. The schematic diagram for the modifies gas-to-liquid technology.

based catalysts, polymerisation of methylene chloride $\left(\mathrm{CH}_{2} \mathrm{Cl}_{2}\right)$ and $\mathrm{CHCl}_{3}$ to hydrocarbons (mainly olefins) was achieved in preliminary work as detail in the next section. Hence, the focus is to maximize the yield and recovery of these compounds for the feasibility of this process.

\subsection{Production of Hydrocarbons}

This study established that hydrocarbons mainly olefins are produced from the polymerisation of $\mathrm{CH}_{2} \mathrm{Cl}_{2}$ and $\mathrm{CHCl}_{3}$ over a typical Fe-based Fischer Tropsch catalysts at industrially relevant conditions. The catalysts were reduced in-situ in the presence of hydrogen.

Catalyst Preparation-A $\mathrm{Fe} / \mathrm{Al}_{2} \mathrm{O}_{3} / \mathrm{Cu}$ catalysts prepared by the method of co-precipitation was employed in this study. Details of the catalyst formulation and preparation steps are reported elsewhere [32]. The precipitate is dried cake and crushed into particles of pre-determined size. The resulting oxyhydroxides were calcined in a fluidized bed reactor using Ar (flow rate $60 \mathrm{ml} / \mathrm{min}$ at NTP) at $350^{\circ} \mathrm{C}$ for $16 \mathrm{hrs}$ using a heating rate of $1{ }^{\circ} \mathrm{C} / \mathrm{min}$. The calcination step removes interstitial water and other volatiles from the solid precursor.

Catalyst Characterization-Nitrogen chemisorption, SEM-EDX and AAS analyses were employed to obtain the surface area, pore size and pore size distribution, pore volume, particle size, elemental distribution and compo- sition of the crystallites respectively. The bulk phases present was studied with XRD while the reducibility of the metal oxides under the reaction conditions was studied using the TPR method (see Rabiu et al. [32] for details).

Reactions - The reactions were conducted in a fixedbed tubular reactor made up of a 3/4-inch OD stainless steel tube and $30 \mathrm{~cm}$ long. The required amount of the calcined catalyst is diluted with enough silicon carbide and packed into the isothermal zone of the tube and secured in place with a glass wool. The catalysts are reduced in-situ with hydrogen flowing at $60 \mathrm{ml} / \mathrm{min}$ (STP) at a temperature ramped at $10^{\circ} \mathrm{C} / \mathrm{min}$ to $350^{\circ} \mathrm{C}$ for $16 \mathrm{hrs}$. Upon completing the reduction, for the reaction with hydrogen, a 3-way valve is used to direct the hydrogen gas to the reactor via a saturator filled with $\mathrm{CH}_{2} \mathrm{Cl}_{2}$ (and later replaced $\mathrm{CHCl}_{3}$ ). The temperature of the saturator is pre-determined such that the desired vapour of the chloromethanes is carried with the hydrogen into the reactor maintained at $1 \mathrm{~atm}$ and $240^{\circ} \mathrm{C}$.

Products Analysis-The setup is fitted with an online GC-TCD to study the activity and an ampoule sampling point (for offline GC-FID analysis) for full products sampling. The GC-TCD is used to obtain the $\mathrm{H}_{2}$ conversions and the methane yield. A $\mathrm{N}_{2}$-cyclohexane mixture was used as internal standard for the GC-FID analysis.

Results-The XRD pattern confirmed that the dominant phase in the calcined samples was haematite. The 
elemental composition was confirmed with AAS and EDX studies (Figure 2). The TPR spectra revealed that a high degree of reduction ( $85 \%$ ) was obtained for the samples reduced at $350^{\circ} \mathrm{C}$. From the GC-FID chromatogram only olefins were observed with ethylene been the most abundant.

Thermodynamic calculation predicts the transformation of the catalyst in the presence of chlorine gas to various iron chlorides: $\mathrm{FeOCl}, \mathrm{FeCl}_{2}$ and $\mathrm{FeCl}_{3}$. The catalyst expectedly suffers rapid deactivation. In Figure 3, the conversion of the hydrogen co-fed to monitor activity declined rapidly after about $22 \mathrm{hrs}$ on stream. XRD analysis of the spent catalysts shown that the catalyst confirmed the presence of $\mathrm{FeCl}_{2}$ and $\mathrm{FeCl}_{3}$ (Figure 4). The catalyst was found to regain its activity after steam was sent to the reactor (as discussed in detail in section 2.4).

\subsection{Recovery of Chlorine}

During the gas-phase methane chlorination reaction, a significant amount of the (natural gas) feedstock is converted to hydrogen chloride gas (as a by-product). Catalytic oxidation, electrolysis and cyclic oxidization processes provide routes for the recovery of chlorine from the

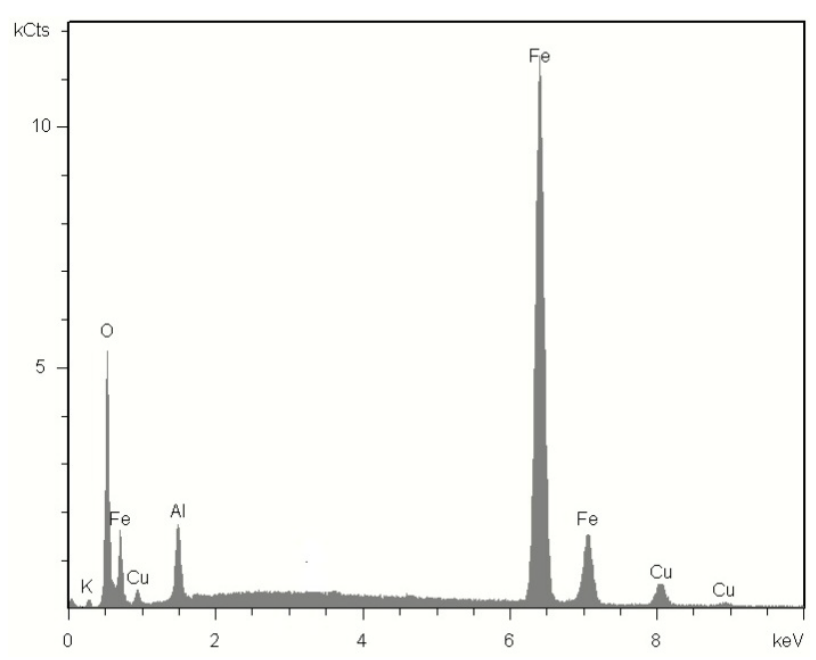

Figure 2. The fresh catalyst EDX pattern.

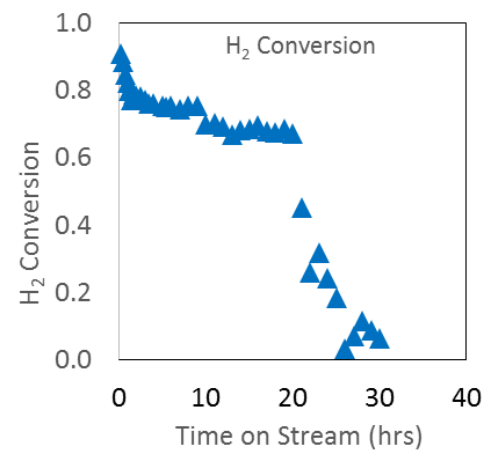

Figure 3. $\mathrm{H}_{2}$ conversion with time.

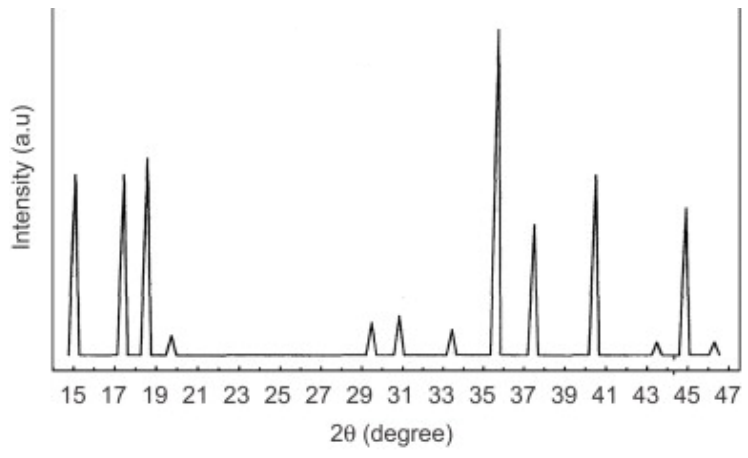

Figure 4. XRD pattern for the spent catalyst.

$\mathrm{HCl}$ [33]. Of particular importance is the heterogeneous catalytic gas-phase oxidation of $\mathrm{HCl}$ with air or oxygen to produce chlorine gas $[34,35]$ as shown in Equation (3):

$$
2 \mathrm{HCl}+\frac{1}{2} \mathrm{O}_{2} \leftrightarrow \mathrm{H}_{2} \mathrm{O}+\mathrm{Cl}_{2}
$$

The so-called Deacon process is a well-established and matured industrial process for large scale manufacturing of high purity chlorine from hydrogen chloride. Compared to the competing electrolytic processes, the Deacon process requires lower energy input [36] and thermal management requirements [37]. A highly active catalyst is required to make the operation of the oxidation process feasible at relatively low temperatures. The original catalyst developed for the Deacon process based on $\mathrm{CuO} /$ $\mathrm{CuCl}_{2}$ suffers from low stability and low activity as a result of formation of volatile copper chloride species due to volatilization of the active phase [38] and the highly corrosive mixture formed by the unreacted $\mathrm{HCl}$ in the presence of water [34]. These have resulted into a limited application of the Deacon process, and the dominance of the electrolytic process for large-scale recovery of chlorine from $\mathrm{HCl}[33,38]$.

The modified-FT process proposed aims to eliminate the use of pure oxygen and the associated cost for air separation facilities. A low temperature process developed by Sumitomo Chemicals employed a highly stable and active $\mathrm{TiO}_{2}$ rutile-supported $\mathrm{RuO}_{2}$ catalyst in a fixedbed reactor configuration $[37,38]$. The uniqueness of the process is that the $\mathrm{RuO}_{2} / \mathrm{TiO}_{2}$ catalyst exhibited a high thermal conductivity and high activity for $\mathrm{HCl}$ oxidation at a relatively low temperature. The catalyst gave very high $\mathrm{HCl}$ conversion up to $90 \%$ at reaction temperatures between $200^{\circ} \mathrm{C}$ and $350^{\circ} \mathrm{C}[34,39]$. The tendency to promote selective and self-regulating surface chlorination while at the same time suppressing in-depth chlorination $[40,41]$ make the catalyst highly stable [39]. The Sumitomo's process requires lower energy input compared with the electrolysis process. A drawback however is the high price of ruthenium, hence this needs to be investigated relative to its benefit. 
An alternative process that employs active but cheaper metal oxide was suggested by Moser [42]. The study investigated various catalyst supports for $\mathrm{CeO}_{2}$ and found that Zirconia gave the best stability and activity. The catalyst was reported to possess excellent thermal conductivity, which reduces hot spots within the catalyst layer. It is therefore proposed for this process and employed at a temperature of $350^{\circ} \mathrm{C}$.

\subsection{Catalysts Regeneration}

As was mentioned earlier, XRD analyses of the spent catalysts shown that the reduced Fe crystallites are readily oxidized to $\mathrm{FeCl}_{2}$ and $\mathrm{FeCl}_{3}$ and probably $\mathrm{FeOCl}$, due to the prevalence of $\mathrm{HCl}$ and gaseous chlorine in the reactor. When steam was passed over the catalyst at elevated temperature, it readily reduced to magnetite according to equation 4 . The catalyst deactivation-regeneration follows:

$$
\begin{gathered}
\mathrm{Fe}_{2} \mathrm{O}_{3}+\mathrm{H}_{2}+\mathrm{Cl}_{2} \rightarrow \mathrm{FeOCl}+\mathrm{FeCl}_{\mathrm{x}}+\mathrm{H}_{2} \mathrm{O} \\
\mathrm{FeOCl}+\mathrm{FeCl}_{\mathrm{x}}+\mathrm{H}_{2} \mathrm{O} \rightarrow \mathrm{Fe}_{3} \mathrm{O}_{4}+\mathrm{HCl}
\end{gathered}
$$

where $\mathrm{x}=2$ and 3

Finally, the FT product is further treated to remove trace of $\mathrm{HCl}$ to permissible level. The $\mathrm{HCl}$ is recovered and recycled.

\section{Conclusion}

It could be seen that the process configuration proposed in this study offers a potential industrial greener process for the direct conversion of natural gas to highly priced olefins which can be further treated for production of high premium gasoline or as chemicals intermediates. The process generated far less carbon dioxide and the products stream is well defined.

\section{Acknowledgements}

The study is supported by the funds provided under the THRIP program of the South African Departments of Trade and Industry and Science and Technology and research fund provided by Cape Peninsula University of Technology.

\section{REFERENCES}

[1] A. Sarkar, R. A. Keogh, S. Bao, et al., "Fischer Tropsch Synthesis with Promoted Iron Catalyst: Reaction Pathways for Acetic Acid, Glycol, 2-Ethoxyethanol and 1,2Diethoxyethane,” Applied Catalysis A, Vol. 341, 2008, pp. 146-153. http://dx.doi.org/10.1016/j.apcata.2008.02.036

[2] J. Gaube and H. F. Klein, "Studies on the Reaction Mechanism of the Fischer-Tropsch Synthesis on Iron and Cobalt," Journal of Molecular Catalysis A: Chemical, Vol. 283, No. 1-2, 2008, pp. 60-68. http://dx.doi.org/10.1016/j.molcata.2007.11.028

[3] BP, "BP Statistical Review of World Energy,” 2013. http://www.bp.com/en/global/corporate/about-bp/statistic al-review-of-world-energy-2013.html

[4] OGJ, "Worldwide Look at Reserves and Production," Oil and Gas Journal, Vol. 110, No. 1, 2012, p. 34.

[5] E. D. Attanasi and P. A. Freeman, "Role of Stranded Gas in Increasing Global Gas Supplies,” US Geological Survey, Open-File Report 2013-1044, 2013. http://pubs.usgs.gov/of/2013/1044

[6] S. G. Podkolzin, E. E. Stangland, M. E. Jones, et al., "Methyl Chloride Production from Methane over Lanthanum-Based Catalysts," Journal of American Chemical Society, Vol. 129, No. 9, 2007, pp. 2569-2576. http://dx.doi.org/10.1021/ja066913w

[7] A. P. Steynberg, "Introduction to Fischer-Tropsch Technology," In: A. P. Steynberg and M. Dry, Eds., Studies in Surface Science and Catalysis: Fischer-Tropsch Technology, Elsevier B.V., Amsterdam, 2004, pp. 1-63. http://dx.doi.org/10.1016/S0167-2991(04)80458-0

[8] D. Wolman, “Gas Goes Solid,” Technology Review, 2003. http://www.technologyreview.com/energy/13157/

[9] B. Svensson and S. Djumena, "A Public-Private Partnership to Reduce Global Gas Flaring,” 2002.

http://www1.worldbank.org/devoutreach/fall02/article.asp ?id=180

[10] T. Obadina, "Harnessing Abundant Gas Reserves in 'Nigeria: Country in Focus',” Africa Recovery, Vol. 13, No. 1, 1999, p. 16.

[11] C. Higman and M. J. van der Burgt, "Gasification,” 2nd Edition, Gulf Publishing Press, 2007, p. 18.

[12] W. Ma, G. Jacobs, Y. Ji, et al., "Fischer-Tropsch Synthesis: Influence of CO Conversion on Selectivities, $\mathrm{H}_{2} / \mathrm{CO}$ Usage Ratios, and Catalyst Stability for a Ru Promoted $\mathrm{Co} / \mathrm{Al}_{2} \mathrm{O}_{3}$ Catalyst Using a Slurry Phase Reactor,” Topics in Catalysis, Vol. 54, No. 13, 2011, pp. 757-767. http://dx.doi.org/10.1007/s11244-011-9699-5

[13] C. G. Visconti, L. Lietti, E. Tronconi, et al., "FischerTropsch Synthesis on a $\mathrm{Co} / \mathrm{Al}_{2} \mathrm{O}_{3}$ Catalyst with $\mathrm{CO}_{2}$ Containing Syngas,” Applied Catalysis A: General, Vol. 355, No. 1-2, 2009, pp. 61-68. http://dx.doi.org/10.1016/j.apcata.2008.11.027

[14] H. C. Heng and S. Idrus, "The Future of Gas to Liquids as a Gas Monetisation Option,” Journal of Natural Gas Chemistry, Vol. 13, 2004, pp. 63-70. jngc.dicp.ac.cn/jngc/2004/2004-02-0063.pdf

[15] A. Holmen, "Direct Conversion of Methane to Fuels and Chemicals,” Catalysis Today, Vol. 142, No. 1-2, 2009, pp. 2-8. http://dx.doi.org/10.1016/j.cattod.2009.01.004

[16] R. B. Anderson, “The Fischer-Tropsch Synthesis,” Academic Press, New York, 1984.

[17] L. A. Noronha, E. F. Souza-Aguiar and C. J. A. Mota, "Conversion of Chloromethane to Light Olefins Catalyzed by ZSM-5 Zeolites,” Catalysis Today, Vol. 101, No. 1, 2005, pp. 9-13. http://dx.doi.org/10.1016/j.cattod.2004.12.004

[18] H. Schulz, "Short History and Present Trends of Fisch- 
er-Tropsch Synthesis,” Applied Catalysis A, Vol. 186, No. 1-2, 1999, pp. 3-12. http://dx.doi.org/10.1016/S0926-860X(99)00160-X

[19] I. T. Horváth, “Encyclopedia of Catalysis,” John Wiley \& Sons, New Jersey, 2003.

[20] Y. Ogawa, K. Hasenaka and Y. Kawasaki, "Research on Marketability of GTL: Liquid Fuel from Natural Gas," IEEJ, 2000. eneken.ieej.or.jp/en/data/old/pdf/gtl.pdf

[21] J. M. G. Carballo, J. Yang, A. Holmen, et al., "Catalytic Effects of Ruthenium Particle Size on the FischerTropsch Synthesis,” Journal of Catalysis, Vol. 284, No. 1, 2011, pp. 102-108. http://dx.doi.org/10.1016/j.jcat.2011.09.008

[22] A. Tavasoli, A. Khodadadi, Y. Mortazavi, et al., "Lowering Methane and Raising Distillates Yields in FischerTropsch Synthesis by Using Promoted and Unpromoted Cobalt Catalysts in a Dual Bed Reactor,” Fuel Processing Technology, Vol. 87, 2006, pp. 641-647. http://dx.doi.org/10.1016/j.fuproc.2006.01.010

[23] P. K. Bakkerud, "Update on Synthesis Gas Production for GTL,” Catalysis Today, Vol. 106, No. 1-4, 2005, pp. 3033. http://dx.doi.org/10.1016/j.cattod.2005.07.147

[24] B. Ghaemmaghami, "GTL: Progress and ProspectsStudy Yields Generic, Coastal-Based GTL Plant,” Oil \& Gas Journal, Vol. 99, No. 11, 2001, pp. 23-31.

[25] M. E. Dry, “The Fischer-Tropsch Process: 1950-2000," Catalysis Today, Vol. 71, No. 3-4, 2002, pp. 227-241. http://dx.doi.org/10.1016/S0920-5861(01)00453-9

[26] D. J. O’Rear and C. L. Kibby, “Control of $\mathrm{CO}_{2}$ Emissions from a Fischer-Tropsch Facility by Use of Multiple Reactors,” United States Patent No. US6992113 B2 2005, International Application No. PCT/US2004/035610.

[27] V. N. Rozanov and Y. A. Treger, "Kinetics of the GasPhase Thermal Chlorination of Methane," Kinetics and Catalysis, Vol. 51, No. 5, 2010, pp. 635-643. http://dx.doi.org/10.1134/S0023158410050034

[28] Y. A. Treger, V. N. Rozanov, S. V. Sokolova, et al., "Producing Ethylene and Propylene from Natural Gas via the Intermediate Synthesis of Methyl Chloride and Its Subsequent Catalytic Pyrolysis," Catalysis in Industry, Vol. 4, No. 4, 2012, pp. 231-235. http://dx.doi.org/10.1134/S2070050412040186

[29] M. C. Alvarez-Galvan, N. Mota, M. Ojeda, et al., "Direct Methane Conversion Routes to Chemicals and Fuels," Catalysis Today, Vol. 171, No. 1, 2011, pp. 15-23. http://dx.doi.org/10.1016/j.cattod.2011.02.028

[30] M. R. Rahimpour, M. Jafari and D. Iranshahi, "Progress in Catalytic Naphtha Reforming Process: A Review,” Applied Energy, Vol. 109, 2013, pp. 79-93. http://dx.doi.org/10.1016/j.apenergy.2013.03.080

[31] J. He, T. Xu, Z. Wang, et al., “Transformation of Me- thane to Propylene: A Two-Step Reaction Route Catalyzed by Modified $\mathrm{CeO}_{2}$ Nanocrystals and Zeolites," Angewandte Chemie, Vol. 124, No. 10, 2012, pp. 24882492. http://dx.doi.org/10.1002/ange.201104071

[32] A. M. Rabiu, E. van Steen and M. Claeys, "Further Investigation into the Formation of Alcohol during Fischer Tropsch Synthesis on Fe-Based Catalysts,” APCBEE Procedia, Vol. 3, 2012, pp. 110-115. http://dx.doi.org/10.1016/j.apcbee.2012.06.055

[33] K. Iwanaga, K. Seki, T. Hibi, et al., "The Development of Improved Hydrogen Chloride Oxidation Process," Vol. 2004, Sumitomo Kagaku, Japan, 2004.

[34] M. A. G. Hevia, A. P. Amrute, T. Schmidt, et al., "Transient Mechanistic Study of the Gas-Phase HCl Oxidation to $\mathrm{Cl}_{2}$ on Bulk and Supported $\mathrm{RuO}_{2}$ Catalysts," Journal of Catalysis, Vol. 276, No. 1, 2010, pp. 141-151. http://dx.doi.org/10.1016/j.jcat.2010.09.009

[35] A. P. Amrute, C. Mondelli, M. Moser, et al., "Performance, Structure, and Mechanism of $\mathrm{CeO}_{2}$ in $\mathrm{HCl}$ Oxidation to $\mathrm{Cl}_{2}$," Journal of Catalysis, Vol. 286, 2012, pp. 287-297. http://dx.doi.org/10.1016/j.jcat.2011.11.016

[36] J. Perez-Ramirez, C. Mondelli, T. Schmidt, et al., "Sustainable Chlorine Recycling via Catalysed HCl Oxidation: From Fundamentals to Implementation,” Energy \& Environmental Science, Vol. 4, No. 12, 2011, pp. 4786-4799. http://dx.doi.org/10.1039/c1ee02190g

[37] N. López, J. Gómez-Segura, R. P. Marín, et al., "Mechanism of $\mathrm{HCl}$ Oxidation (Deacon Process) over $\mathrm{RuO}_{2}$," Journal of Catalysis, Vol. 255, No. 1, 2008, pp. 29-39. http://dx.doi.org/10.1016/j.jcat.2008.01.020

[38] M. Hammes, M. Valtchev, M. B. Roth, et al., "A Search for Alternative Deacon Catalysts,” Applied Catalysis B: Environmental, Vol. 132-133, 2013, pp. 389-400. http://dx.doi.org/10.1016/j.apcatb.2012.11.034

[39] H. Over and R. Schomäcker, "What Makes a Good Catalyst for the Deacon Process?” ACS Catalysis, Vol. 3, No. 5, 2013, pp. 1034-1046.

[40] J. P. Hofmann, S. Zweidinger, A. P. Seitsonen, et al., "Dynamic Response of Chlorine Atoms on a $\mathrm{RuO}_{2}(110)$ Model Catalyst Surface," Physical Chemistry Chemical Physics, Vol. 12, No. 47, 2010, pp. 15358-15366. http://dx.doi.org/10.1039/c0cp01126f

[41] S. Zweidinger, J. P. Hofmann, O. Balmes, et al., "In-Situ Studies of the Oxidation of $\mathrm{HCl}$ over $\mathrm{RuO}_{2}$ Model Catalysts: Stability and Reactivity,” Journal of Catalysis, Vol. 272, No. 1, 2010, pp. 169-175. http://dx.doi.org/10.1016/j.jcat.2010.02.030

[42] M. Moser, C. Mondelli, T. Schmidt, et al., "Supported $\mathrm{CeO}_{2}$ Catalysts in Technical Form for Sustainable Chlorine Production,” Applied Catalysis B: Environmental, Vol. 132-133, 2013, pp. 123-131. http://dx.doi.org/10.1016/j.apcatb.2012.11.024 